\title{
The construction of the teaching system of progressive practice based on the concept of Engineering
}

\author{
BaiYan $^{1, a}$, Zheng Wengang ${ }^{2}$, Weiliang ${ }^{3, c}$ \\ ${ }^{1}$ BeiHua University Engineering Training Center \\ ${ }^{2}$ Beihua University Mechanical Engineering College \\ ${ }^{3}$ Jilin Electric Power Co., Ltd. power supply company of Changchun \\ a745575912@qq.com b,c byw1689@sohu.com,
}

\section{Keywords: Practice teaching; Engineering concept; Engineering skills}

\begin{abstract}
Higher education is an important pillar of the national construction, undertaking the three functions of personnel training, scientific research and social services. Aiming at the problems existing in the practical teaching of colleges and universities. This paper puts forward the new mode of the gradual practice teaching, which is the reform of the teaching mode, the key is to improve the engineering concept of college students, the breakthrough point is based on the differences between students' individual cognition, outstanding training of engineers skills.
\end{abstract}

\section{Introduction}

In recent years from the enterprise human resources management departments of the research conclusion, the University of engineering graduates overall engineering skills are low, hands-on ability is poor, theoretical knowledge is not solid, engineering quality is low, the lack of a sense of collective sense of honor and responsibility, lack of engineering technology, engineering safety, engineering quality, engineering, environment consciousness, into the role of the engineer slower, then the improvement and improve college students of engineering expertise and engineering quality training is imperative, which promote the cultivation of students' engineering awareness and skills is a great challenge facing the higher engineering college education ${ }^{[1-3]}$

\section{The construction of the practical teaching system of the ladder type}

The cultivation of engineering ability is to require students to be able to do the theory with practice, to apply the theory to the engineering research, design, construction and other aspects, and comprehensively consider the technology, environment, safety, the impact of the law on the project.But the cultivation of engineering ability is restricted by many factors, such as the teaching task. Now most of the colleges and universities focus on theory teaching and practice teaching, the theoretical teaching of the whole school year teaching task of $90 \%$, and left to the practice link only $10 \%$, resulting in poor students practical ability, The author thinks that the correct arrangement of should is the theory and practice of 4:3 structure, to gradually shorten the disparity of the practical teaching and theoretical teaching schedule, give the students enough time to practice learning, colleges and universities should attach importance to practice teaching, practice teaching should is the essence of engineering ability cultivation, today in the rapid development of science and technology, for Industry and trade colleges excellent engineering skills training program is no longer a stick in the mud of the general education, but a breakthrough education to cultivating students' ability to analyze problems, to solve the problem and the independent design of practical ability.Cultivate their creative ability and innovative thinking, so that they will be from the actual case of the market to avoid unsafe risks and technical risks, through an open mind and a keen insight into new ideas and new ideas. The author divides the ladder type practical teaching system (take the automation technology as an example) into two parts, which is composed of two parts, which are used to improve the application ability of students' professional knowledge, analyze and solve the problems, engineering design capability, and the ability to work together. The concrete 
structure is shown in Figure 1.

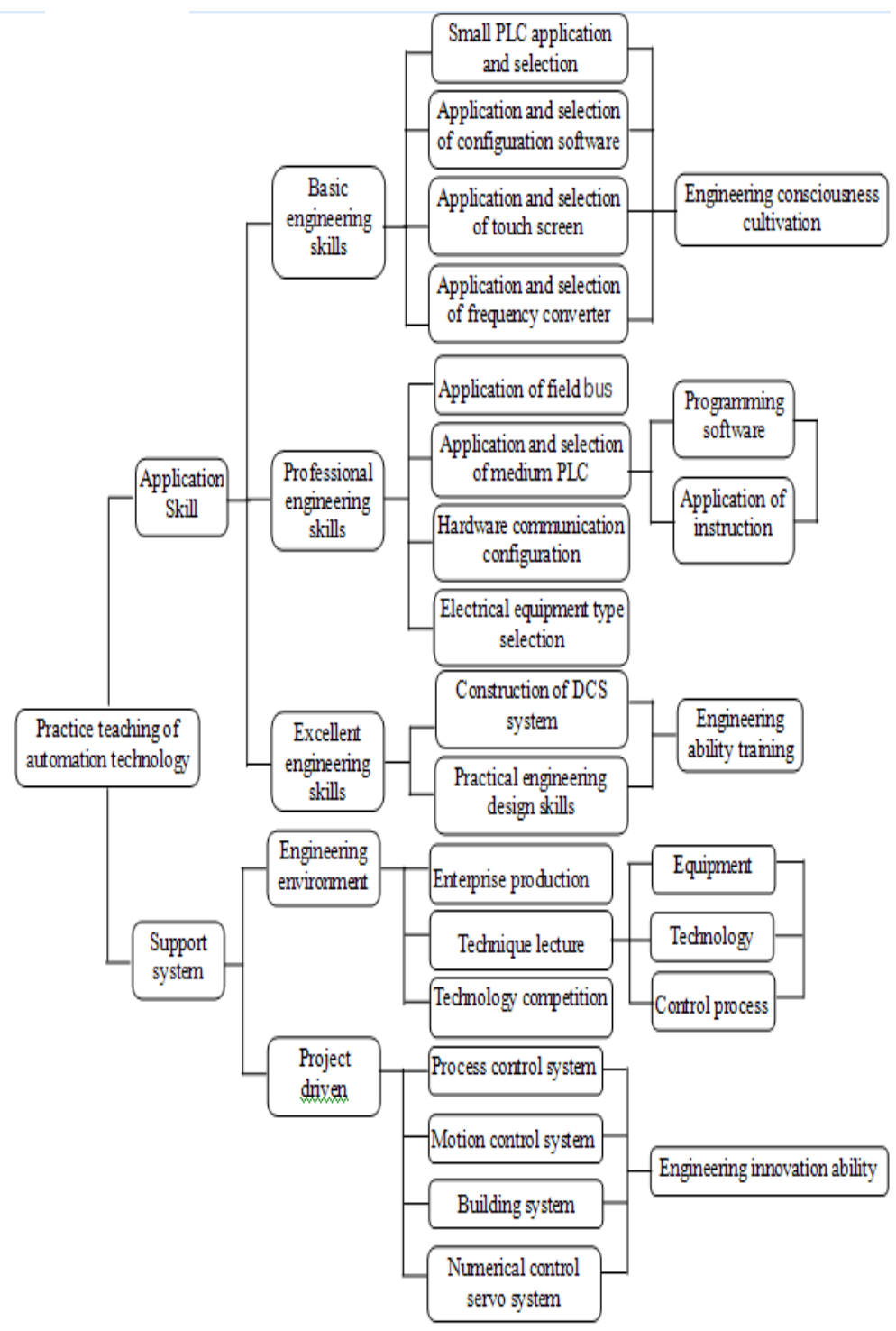

Fig. 1 Ladder type practice teaching system structure diagram

A.In the basic engineering skills training link, pay attention to the educated application ability culture, for example in automation technology practice teaching link of engineering skills training, programming controller only to have the ability of program design, electrical schematics of reading and drawing ability; in the use of configuration software to focus on configuration interface design, drawing, programming the command of the language; touch screen use and frequency of use. This layer of teaching for the distributed control system is built the most important control technology, aims to cultivate educated engineering consciousness, basic engineering capabilities. In this part of the education, because of the individual differences, there will be a number of winners will be completed in advance of the task smoothly into the teaching of professional engineering skills training.

B.In engineering skills training links, with basic engineering skills training aspects of the application of knowledge is the foundation of the research, mastery of knowledge and control system, to learn the use of field bus, through the use of different field bus complete hardware configuration, the establishment of upper machine and lower machine communication, at the same time with independently according to the ability to control task complete electrical equipment and components selection, for excellence in engineering skills to lay a solid foundation, this stage is to improve overall instructed the engineering quality and practice ability training.

C.In engineering excellence skills training links, there will be few educated was singled out. These educated will in this section is composed of a team of visiting companies actual 
environmental engineering and production engineering, and according to the control task is completed from the project, engineering design, engineering safety, engineering implementation And so on 360 degree all aspects of the engineering capacity strengthening design training. Finally, the ability to achieve excellence engineers, so that it has the ability to project innovation.

\section{The level of practical teaching system of project tasks}

Project can be divided into many categories, we take the sewage treatment control process as an example, the teaching level of the practice teaching system and the teaching level of the practice content.

\section{Variable frequency constant pressure water supply system.}

The process is designed to be a water filtration process as an example. The whole process is divided into two parts: the normal constant water level filtration and the air water back flushing process. The normal constant water level filter process using the ladder diagram of the main program to achieve, according to the logic of the main program to call the subroutine of the air water reverse flushing process. So that we can achieve the smooth implementation of the whole control process.PID control is a simple structure of the controlled object, a simple structure of the algorithm, the control law is:

$$
u(t)=K_{p}\left(e(t)+\frac{1}{T_{i}} \int_{0}^{t} e(t) d t+\frac{T_{d} e(t)}{d t}\right)
$$

Transfer function:

$$
G(s)=\frac{U(s)}{E(s)}=K_{p}\left(1+\frac{1}{T_{i} s}+T_{d} s\right)
$$

Incremental PID control method is generally used in the constant pressure water supply water supply, and its discrete form is:

$$
\Delta u(k)=K_{p}[e(k)-e(k-1)]+K_{i} e(k)+K_{d}[e(k)-2 e(k-1)+e(k-2)]
$$

$k$ For the use of serial number, $\Delta u(k)$ Output control for a certain time, ${ }^{e(k)}$ Error for a certain moment.

Variable frequency constant pressure water supply system diagram as shown in Figure.2.

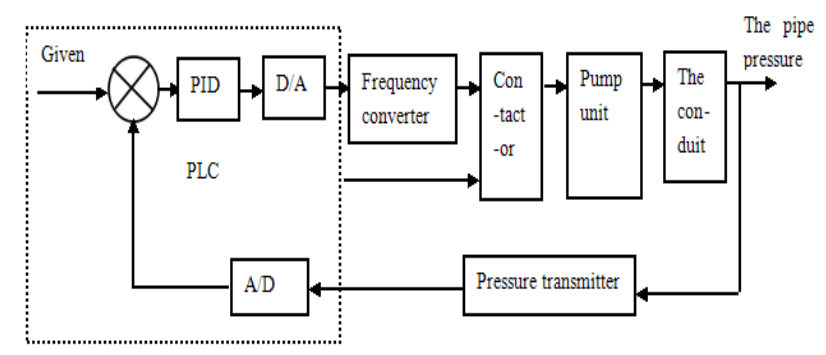

Fig. 2 Variable frequency constant pressure water supply system

\section{Application of T-S model.}

The T-S model can be used to generate more complex nonlinear functions, which can effectively reduce the number of fuzzy rules in the process of dealing with multi variable systems. However, the conclusion is that the parameters of the linear function are not fuzzy number, the conclusion part of the actual system can not be directly obtained from the expert experience and operational data. Therefore, the identification of the model parameters is the main problem in the establishment of the T-S type fuzzy system.

In this paper, the T-S model and PID control can achieve the optimal control effect. If the control effect is not reached, the combination method of PID and T-S can be used to adjust the PID regulation. T-S model is an effective model to solve the nonlinear problem, which can describe the 
dynamic characteristics of the nonlinear system, so it has been widely used. The T-S model and PID control can be used to control the constant pressure water supply system. TS-PID is more effective than PID in parameter adjustment, which is assumed to have $\mathrm{M}$ rule, then the i rule is:

$$
\begin{aligned}
& R^{i}: \text { if } h_{3} \text { is } A^{i}, \text { then } \\
& k_{P}=k_{p}^{i}, k_{i}=k_{i}^{i}, k_{d}=k_{d}^{i},(i=1,2 \ldots) \\
& K_{P}=\frac{\sum_{i=1}^{n} w_{A^{\prime}} k_{p}^{i}}{\sum_{i=1}^{n} w_{A^{\prime}}} ; K_{i}=\frac{\sum_{i=1}^{n} w_{A^{\prime}} k_{i}^{i}}{\sum_{i=1}^{n} w_{A^{\prime}}} ; K_{d}=\frac{\sum_{i=1}^{n} w_{A^{\prime}} k_{d}^{i}}{\sum_{i=1}^{n} w_{A^{\prime}}}
\end{aligned}
$$

$w_{A^{\prime}}$ is the application degree of fuzzy language rule, A as the fuzzy subset, $h$ is the state of the controlled object, and the output variables are the parameters of PID.

Application of MATLAB.

MATLAB is a commercial mathematics software produced by Math Works company, which is used in the development of algorithms, data visualization, data analysis and numerical calculation of advanced technology and interactive environment, mainly including MATLAB and Simulink two parts.It provides a comprehensive solution for scientific research, engineering design, and many scientific fields of the nonlinear dynamic system modeling and simulation, which will be integrated in an easy to use window environment.The simulation model is shown in Figure 3.

The PID control algorithm and the T-S model are combined to get a good control effect, the simulation results are shown in Figure 4, you can see that once the interference factors, the system can quickly respond to maintain stability.PID PLC program are shown in Figure 5.

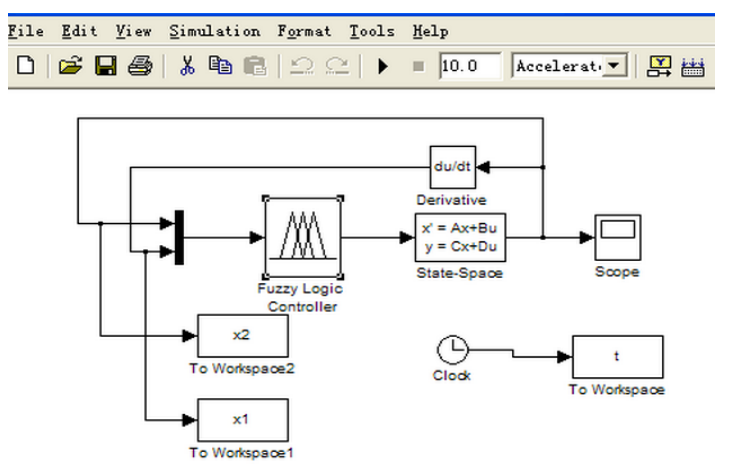

Fig. 3 simulation mode

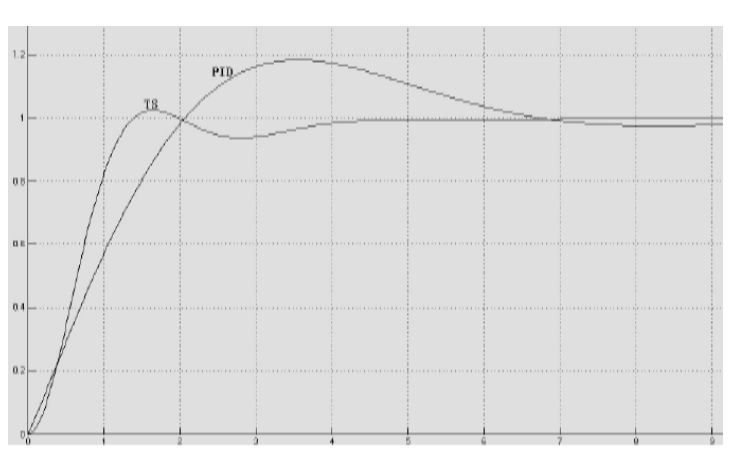

Fig. 4 simulation results

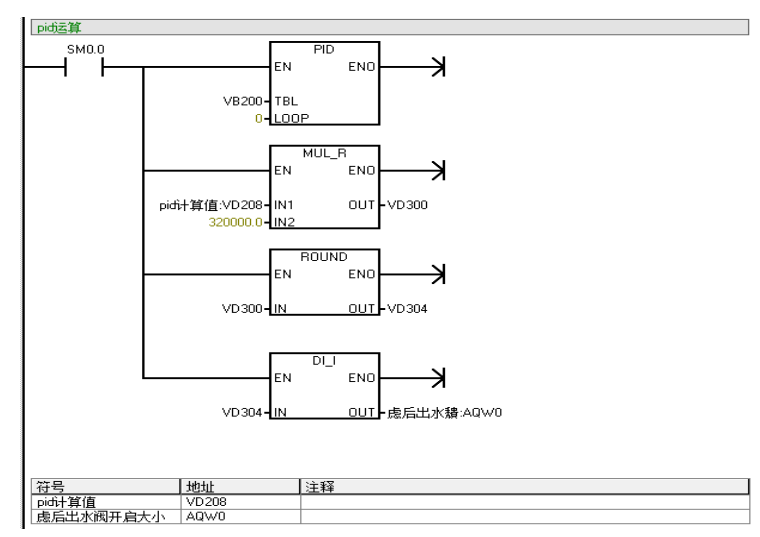

Fig. 5 PID PLC program

PID control and it s control algorithm:

$$
y(t)=K_{p}\left[e(t)+\frac{1}{T_{i}} \int e(t) d t+T_{d} \frac{d e(t)}{d t}\right]
$$




$$
G(s)=\frac{U(s)}{E(s)}=K_{P}\left(1+\frac{1}{T_{i} s}+T_{d} s\right)
$$

The system can be approximated as a first order inertial link with pure lag[6], the process of

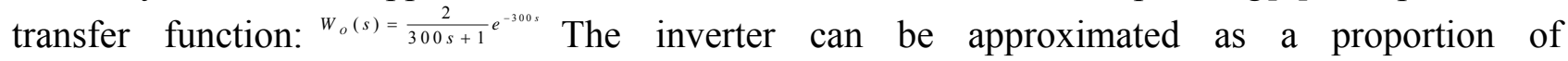
links, ${ }_{W_{v}}(s)=50$.The feedback loop transfer function: ${ }^{\prime}(s)=0.03$ Because the system has the self regulating ability, The PI controller transfer function:

$$
W_{C}(s)=\frac{1}{3}\left(1+\frac{1}{240 s}\right)=\frac{240 s+1}{720 s}
$$

Using MATLAB simulation software, programming is as follows:

$$
s 1=t f(2,[300,1]) ; s 2=t f([240,1],[720,0]) ; s k=s 1 * s 2 * 50 ; s=\text { feedback }(s k, 0.03) ; \operatorname{step}(s) \text {; }
$$

\section{Configuration interface design.}

The central control room host computer monitoring and control configuration software using SIEMENS WINCC6.2 configuration software design, the software is powerful, the interface is beautiful, the design process is simple, and can display the process of running water, and the central control room is equipped with a large scale simulation screen, which reflects the process of the display, security and unified display, fault alarm.Configuration interface design as shown in Figure6.

Comprehensive monitoring and management system is perfect, with the advantages of data management, equipment optimization, energy saving, not only improve the utilization of equipment, but also reduce the labor intensity, therefore, has a certain practical application value.

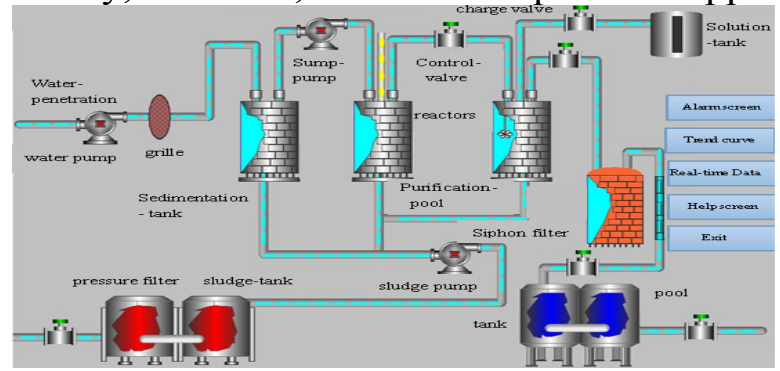

Fig. 6. The configuration screen of monitoring management

\section{The dynamic interface program design.}

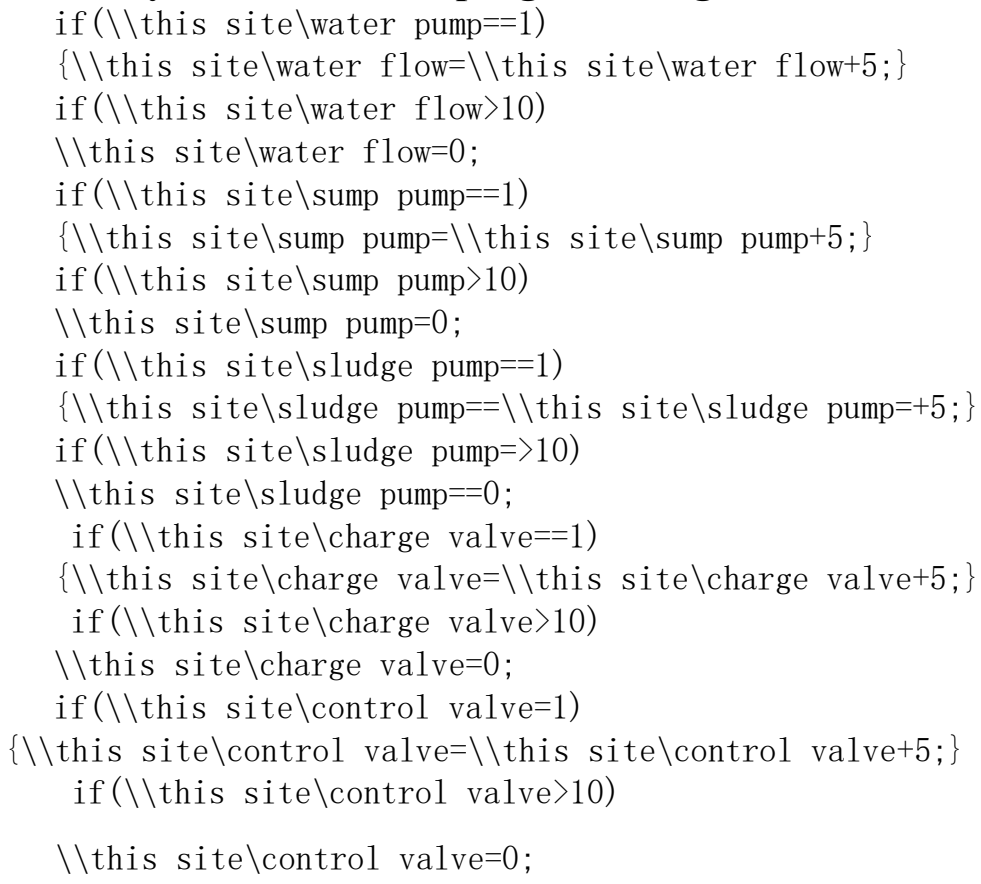




\section{Conclusion}

This paper is based on the advanced concept of higher education in developed countries and engineering education, based on the engineering concept to improve the professional practice teaching system, based on the professional basis for the core, with the ability to develop and innovation ability training as the goal, to promote the formation of a reasonable model of the first line engineers to develop.

\section{References}

[1] Wan T J.An application of artificial neuromolecular system for effluent quality prediction of wastewater treatment plant. Chinese Instrument Environment Engineering. 2000

[2] Jiang Wei. System Identification Methods and Applications. National Defence Industry Press. 2010

[3] M Batty.The AJAX project:New theory, and new software for space syntax[J].SPACE SYNTAX 5TX INTERNATIONAL SYMPOSIUM 2005,VOL 1,PROCEEDINGS.2005,(12/1):10 11

[4] Chen J C,Chang N B.Assessing wastewater reclamation potential by neural network model. Engineering Applications of Artificial Intelligence. 2003

[5] Du Y G,Tyagi R D,Bhamidimarri R.Use of fuzzy neural-net model for rule generation of activated sludge process. Process Biochemistry. 1999 